\title{
Correlations between Perceived Oral Malodor Levels and Self-Reported Oral Complaints
}

\author{
Atsushi Kameyama, ${ }^{1,2}$ Kurumi Ishii, ${ }^{3}$ Sachiyo Tomita, ${ }^{4}$ Chihiro Tatsuta, ${ }^{3}$ \\ Toshiko Sugiyama, ${ }^{2}$ Yoichi Ishizuka, ${ }^{5}$ Toshiyuki Takahashi, ${ }^{2}$ and Masatake Tsunoda ${ }^{2}$ \\ ${ }^{1}$ Department of Endodontics and Clinical Cariology, Tokyo Dental College, Tokyo, Japan \\ ${ }^{2}$ Division of General Dentistry, Tokyo Dental College Chiba Hospital, Chiba, Japan \\ ${ }^{3}$ Tokyo Dental College School of Dental Hygiene, Chiba, Japan \\ ${ }^{4}$ Department of Periodontology, Tokyo Dental College, Tokyo, Japan \\ ${ }^{5}$ Department of Epidemiology and Public Health, Tokyo Dental College, Tokyo, Japan
}

Correspondence should be addressed to Atsushi Kameyama; kameyama@tdc.ac.jp

Received 3 March 2015; Accepted 2 July 2015

Academic Editor: Manuel Lagravere

Copyright (C) 2015 Atsushi Kameyama et al. This is an open access article distributed under the Creative Commons Attribution License, which permits unrestricted use, distribution, and reproduction in any medium, provided the original work is properly cited.

Objectives. Even though objective data indicating the absence of oral malodor are presented to patients, they may be skeptical about the results, possibly due to the presence of some discomfort in the oral cavity. The objective of this study was to investigate whether there is an association among self-perceptions of oral malodor, oral complaints, and the actual oral malodor test result. Materials and Methods. Questions concerning self-perceptions of oral malodor and subjective intraoral symptoms were extracted from a questionnaire on oral malodor completed by 363 subjects who visited the clinic for oral malodor of Tokyo Dental College Chiba Hospital and gave consent to this study. In addition, the association of self-perception of oral malodor with values obtained after organoleptic and OralChroma measurement was analyzed. Results. No correlation between 195 subjects (54\%) who were judged "with oral malodor" (organoleptic score of $\geq 1$ ) and 294 subjects $(81.6 \%)$ who had a self-perceptions of oral malodor was observed. Self-perception of oral malodor was significantly correlated with tongue coating $(p=0.002)$ and a strange intraoral taste $(p=$ 0.016). Conclusions. Subjects with a self-perception of oral malodor were not necessarily consistent with those actually having an oral malodor. In addition, it was suggested that patients became aware of oral malodor when they felt oral complaints.

\section{Introduction}

Increasing awareness of cleanliness by society in general has heightened interest in odor. Since one cannot sense oral malodor accurately by oneself, bad breath brings marked psychological discomfort and may interfere with social interactions [1]. Many people feel anxiety or distress regarding oral malodor, even though they may have no such oral malodor. They may believe they have oral malodor when they see someone touching his/her nose or grimacing during a conversation [2].

Even though a dentist judges the oral malodor level by smelling and informs patients that there is no oral malodor, it is difficult for them to accept it because the procedure is based on the examiner's subjectivity. Therefore, it is necessary to measure the actual oral malodor level by measuring major oral malodor-related volatile sulfur compounds (VSCs) contained in exhaled air, hydrogen sulfide $\left(\mathrm{H}_{2} \mathrm{~S}\right)$, methyl mercaptan $\left(\mathrm{CH}_{3} \mathrm{SH}\right)$, and dimethyl sulfide $\left(\left(\mathrm{CH}_{3}\right)_{2} \mathrm{~S}\right)$, and "objectively" inform patients of the actual oral malodor level [3]. Many pseudohalitosis patients are convinced and relieved when the examiner (dentists and dental hygienists) inform them that there is no need to worry about oral malodor by showing the VSC measurement results $[3,4]$.

On the other hand, some people visiting an outpatient clinic for oral malodor are skeptical even though these objective data are presented [5]. They may be diagnosed with "halitophobia" based on the classification reported by Murata 
et al. [6]. However, if they have some subjective intraoral symptoms (self-reported oral complaints), these may induce pseudohalitosis or real malodor. If so, their distress caused by oral malodor is not resolved unless oral complaints are resolved. Therefore, it is necessary to investigate whether there is an association between a self-perception of oral complaints and actual manifestation of oral malodor or number of complaints of pseudohalitosis.

To clarify the association between the presence or absence of oral complaints and actual oral malodor measurement results, it was necessary to investigate the association between various subjective intraoral symptoms and oral malodor parameters (VSCs) in subjects who initially visited the outpatient clinic for oral malodor of Tokyo Dental College Chiba Hospital. The following null hypotheses were set: (1) there is no correlation between self-perceptions of oral malodor and oral complaints and (2) there is no correlation between selfperception of oral malodor and oral malodor parameters.

\section{Materials and Methods}

2.1. Subjects. Of a total of 429 persons who visited the outpatient clinic for oral malodor at the Tokyo Dental College Chiba Hospital between January 2009 and December 2011, 363 (123 males and 240 females) gave written consent after an explanation of the objective of the study. Four of them were excluded because of data deficiency. This study was performed after approval by the Ethics Committee of Tokyo Dental College (protocol approval number 375 ).

2.2. Extraction of Responses to Questionnaire concerning Oral Malodor. All initial examinees completed to a self-administered questionnaire concerning oral malodor before examination of the oral cavity and the oral malodor test. Questions concerning the presence or absence of subjective oral malodor symptoms and related items (11 items in total) were extracted and adopted for this study as follows.

Questionnaire on Oral Malodor Responded to by Examinees of the Outpatient Clinic for Oral Malodor of Tokyo Dental College Chiba Hospital (List of Factors concerning Oral Complaints).

(1) Do you think you have bad breath?

(Yes/No/Unsure)

(2) Do your gums bleed during tooth brushing?

(Yes/No)

(3) Do your gums ooze out pus?

(Yes/No)

(4) Do you have a loose tooth/teeth?

(Yes/No)

(5) Do you grind your teeth while you are asleep?

(Yes/No)
(6) Does your mouth feel dry?

(Yes/No)

(7) Is your mouth viscous?

(Yes/No)

(8) Is your tongue frequently coated with deposits?

(Yes/No)

(9) Do you often remove tongue coating?

(Yes/No)

(10) Do you notice a bad taste in your mouth?

$(\mathrm{Yes} / \mathrm{No})$

(11) Is there medicine you have to take regularly?

(Yes/No)

2.3. Evaluation of Oral Malodor Level. The oral malodor level was objectively evaluated by measuring the levels of 3 volatile sulfur compounds (VSCs) contained in intraoral gas using a portable gas chromatograph, OralChroma (FIS, Itami, Hyogo, Japan), and performing an organoleptic test.

To gather optimal test results, several precautions should be taken before the examinations: the patient should refrain from eating spicy foods, garlic, or onions the day before the examination. For at least $12 \mathrm{~h}$ before the consultation, the teeth should not be cleaned or rinsed, perfumes should be avoided, and, at least $6 \mathrm{~h}$ before the examination, the intake of food and liquids should be avoided. Smoking should be refrained from for at least $24 \mathrm{~h}$ before any examination [7].

To use breath odor at waking as the standard, measurement was performed between 9:30-11:30 a.m. [8]. The organoleptic test was performed employing 5-step grading: scores $0=$ absence of odor, $1=$ barely appreciable odor, 2 = moderate malodor, $3=$ strong malodor, and $4=$ severe malodor.

Prior to measurement using OralChroma, the patients were instructed to close their mouth and breathe through their nose for 30 seconds. A 1-mL disposable syringe (Top, Tokyo, Japan) was placed in the mouth through the lips and teeth, $1 \mathrm{~mL}$ of air in the mouth was aspirated, and $0.5 \mathrm{~mL}$ of this was immediately injected into OralChroma [9]. It was judged that oral malodor can be perceived when the $\mathrm{H}_{2} \mathrm{~S}$ level exceeds $600 \mathrm{ppb}$, the $\mathrm{CH}_{3} \mathrm{SH}$ level exceeds $100 \mathrm{ppb},\left(\mathrm{CH}_{3}\right)_{2} \mathrm{~S}$ level exceeds $100 \mathrm{ppb}[2,10]$, or organoleptic level is $1-4$.

2.4. Analysis. The associations between self-perception of oral malodor and each subjective intraoral symptom and oral malodor parameter were investigated using the Chisquare test ( $p=0.05)$. When data involved only 20 or fewer subjects, Yates' correction was applied. The association between the parameters was analyzed using Spearman's rankcorrelation coefficient test. Statistical analysis was performed using IBM SPSS statistics 18 for Windows (IBM Japan Inc., Tokyo, Japan). 
TABLE 1: Correlation coefficients between the results of 4 parameters regarding oral malodor.

\begin{tabular}{lcccc}
\hline & $n$ & \multicolumn{3}{c}{ Spearman's correlation } \\
& & $\mathrm{CH}_{3} \mathrm{SH}$ & $\left(\mathrm{CH}_{3}\right)_{2} \mathrm{~S}$ & $\mathrm{OT}$ \\
\hline $\mathrm{H}_{2} \mathrm{~S}$ & & & & \\
$<600 \mathrm{ppb}$ & 335 & $r=0.247$ & $r=0.449$ & $r=0.422$ \\
$\geq 600 \mathrm{ppb}$ & 24 & $p<0.001$ & $p<0.001$ & $p<0.001$ \\
$\mathrm{CH}_{3} \mathrm{SH}$ & & & & \\
$<100 \mathrm{ppb}$ & 165 & & $p<0.294$ & $r=0.906$ \\
$\geq 100 \mathrm{ppb}$ & 194 & & & $p<0.001$ \\
$(\mathrm{CH})_{2} \mathrm{~S}$ & & & & \\
$<100 \mathrm{ppb}$ & 305 & & & \\
$\geq 100 \mathrm{ppb}$ & 54 & & & \\
$\mathrm{OT}$ & & & & \\
Score 0 & 164 & & & \\
Score 1 & 83 & & & \\
Score 2 & 59 & & & \\
Score 3 & 26 & & & \\
Score 4 & 27 & & & \\
\hline
\end{tabular}

OT: organoleptic test; $n$ : number of subjects.

$r$ : correlation coefficient.

\section{Results}

3.1. Correlation between Oral Malodor Parameters. The associations among the 4 oral malodor parameters are shown in Table 1. Significant correlations were noted between the parameters of all combinations $(p<0.001)$. Particularly, a strong correlation was noted between the organoleptic test result and $\mathrm{CH}_{3} \mathrm{SH}(r=0.906, p<0.001)$.

\subsection{Association between Self-Perception of Oral Malodor and} Oral Malodor Parameters. Only 9 (2.5\%) of the 359 subjects responded that they were not aware of their own oral malodor, 294 subjects $(81.9 \%)$ responded that they had selfperceived oral malodor, and 56 subjects (15.6\%) stated that they did not know. The results of analysis of the association between self-perception of oral malodor and the results of VSC measurement using OralChroma and the organoleptic test are shown in Table 2. Subjects who chose "unsure" to the questions on self-perception of oral malodor were regarded as having no self-perception. No significant correlation with the presence or absence of self-perception of oral malodor was noted in any of $\mathrm{H}_{2} \mathrm{~S}, \mathrm{CH}_{3} \mathrm{SH},\left(\mathrm{CH}_{3}\right)_{2} \mathrm{~S}$, or organoleptic test results.

3.3. Association between Self-Perception of Oral Malodor and Oral Complaints. The results of analysis of the association between self-perception of oral malodor and elements of oral complaints are shown in Table 3. No significant correlation was noted between the presence or absence of periodontal disease-associated intraoral symptoms and self-perception of oral malodor. In contrast, a significant correlation was noted between tongue coating and self-perception of oral malodor $(p=0.002)$. A significant correlation with a strange intraoral
TABLE 2: Relationships between self-perception of oral malodor and associated parameters.

\begin{tabular}{cccc}
\hline & \multicolumn{2}{c}{ Self-perceived oral malodor } & p value \\
& $(+)(n=294)$ & $(-)(n=65)$ & \\
\hline $\mathrm{H}_{2} \mathrm{~S}$ & & & \\
$<600 \mathrm{ppb}$ & 22 & 2 & $0.311 \mathrm{NS}$ \\
$\geq 600 \mathrm{ppb}$ & 272 & 63 & \\
$\mathrm{CH}_{3} \mathrm{SH}$ & & & \\
$<100 \mathrm{ppb}$ & 153 & 41 & $0.106 \mathrm{NS}$ \\
$\geq 100 \mathrm{ppb}$ & 141 & 24 & \\
$(\mathrm{CH})_{2} \mathrm{~S}$ & & & \\
$<100 \mathrm{ppb}$ & 46 & 8 & \\
$\geq 100 \mathrm{ppb}$ & 248 & 57 & \\
Organoleptic test & & & \\
Score 0 & 140 & 24 & \\
Score 1 & 63 & 20 & \\
Score 2 & 49 & 10 & \\
Score 3 & 18 & 8 & \\
Score 4 & 24 & 3 & \\
\hline
\end{tabular}

NS: no significant difference (Chi-square test).

taste was also observed ( $p=0.016$ ), but no significant correlation with intraoral viscosity was noted $(p=0.067)$.

The combinations of significantly correlated factors on analysis using Spearman's correction are shown in Table 4. Significant correlations were noted between oral dryness and intraoral viscosity, a strange taste, tongue coating, and frequent tongue brushing $(p<0.05)$. In addition, significant correlations were noted between intraoral viscosity and tongue coating and a strange intraoral taste $(p<0.05)$.

\section{Discussion}

The objective of this study was to clarify the association between the presence or absence of subjective intraoral symptoms and results of actual oral malodor measurement. The oral malodor level was judged based on the measurement of 3 VSCs, in addition to the organoleptic test. The organoleptic test is considered to be the gold-standard oral malodor test because whether oral malodor is perceived by human olfaction is important for the judgment of the presence or absence of oral malodor [11, 12]. However, tests employing human olfaction cannot be quantified because it is based on subjective judgment by the examiner (operator). Therefore, comparison of the test results between before and after treatment is difficult, and the test lacks persuasiveness as a material for explanation of the oral malodor level [3]. Therefore, to judge the oral malodor level, generally, the measurement of oral malodor-producing substances using an oral malodor-analyzing device is concomitantly employed in addition to the olfaction-based organoleptic test.

The organoleptic score is correlated with the levels of VSCs contained in intraoral gas determined using gas chromatography and a portable sulfide monitor. We also observed correlations among the 4 items: the $\mathrm{H}_{2} \mathrm{~S}, \mathrm{CH}_{3} \mathrm{SH}$, 
TABLE 3: Relationships between self-perception of oral malodor and oral complaints.

\begin{tabular}{|c|c|c|c|}
\hline \multicolumn{3}{|c|}{ Self-perceived oral malodor } & \multirow{2}{*}{$p$ value } \\
\hline & $(+)$ & $(-)$ & \\
\hline \multicolumn{4}{|c|}{ Bleeding from gum } \\
\hline Yes & 83 & 19 & \multirow{2}{*}{$0.872 \mathrm{NS}$} \\
\hline No & 211 & 46 & \\
\hline \multicolumn{4}{|c|}{ Pus from gum } \\
\hline Yes & 27 & 2 & \multirow{2}{*}{$0.167 \mathrm{NS}$} \\
\hline No & 267 & 63 & \\
\hline \multicolumn{4}{|c|}{ Tooth movement } \\
\hline Yes & 29 & 9 & \multirow{2}{*}{$0.471 \mathrm{NS}$} \\
\hline No & 265 & 56 & \\
\hline \multicolumn{4}{|c|}{ Grinding of teeth } \\
\hline Yes & 58 & 14 & \multirow{2}{*}{$0.742 \mathrm{NS}$} \\
\hline No & 236 & 51 & \\
\hline \multicolumn{4}{|c|}{ Mouth dryness ${ }^{*}$} \\
\hline Yes & 181 & 29 & \multirow{2}{*}{0.012} \\
\hline No & 113 & 36 & \\
\hline \multicolumn{4}{|c|}{ Intraoral viscosity } \\
\hline Yes & 192 & 36 & \multirow{2}{*}{$0.133 \mathrm{NS}$} \\
\hline No & 102 & 29 & \\
\hline \multicolumn{4}{|c|}{ Tongue coating* } \\
\hline Yes & 200 & 31 & \multirow{2}{*}{0.002} \\
\hline No & 94 & 34 & \\
\hline \multicolumn{4}{|c|}{ Frequent tongue brushing } \\
\hline Yes & 181 & 32 & \multirow{2}{*}{$0.067 \mathrm{NS}$} \\
\hline No & 113 & 33 & \\
\hline \multicolumn{4}{|c|}{ Strange taste ${ }^{*}$} \\
\hline Yes & 99 & 12 & \multirow{2}{*}{0.016} \\
\hline No & 195 & 53 & \\
\hline \multicolumn{4}{|c|}{ Taking medicine } \\
\hline Yes & 141 & 27 & \multirow{2}{*}{$0.348 \mathrm{NS}$} \\
\hline No & 153 & 38 & \\
\hline
\end{tabular}

${ }^{*}$ Significant difference (Chi-square test; $\left.p<0.05\right)$.

TABLE 4: Correlated parameters analyzed by Spearman's correlation.

\begin{tabular}{llcc}
\hline & & $r$ & $p$ value \\
\hline Bleeding from gum & Pus from gum & 0.153 & 0.004 \\
\hline Tooth movement & Grinding of teeth & 0.122 & 0.021 \\
\hline \multirow{3}{*}{ Mouth dryness } & Intraoral viscosity & 0.289 & $<0.001$ \\
& Tongue coating & 0.199 & $<0.001$ \\
& Strange taste & 0.197 & $<0.001$ \\
& Frequent tongue cleaning & 0.108 & 0.040 \\
\hline \multirow{2}{*}{ Intraoral viscosity } & Tongue coating & 0.269 & $<0.001$ \\
& Strange taste & 0.232 & $<0.001$ \\
\hline \multirow{2}{*}{ Tongue coating } & Frequent tongue cleaning & 0.355 & $<0.001$ \\
& Strange taste & 0.259 & $<0.001$ \\
\hline
\end{tabular}

and $\left(\mathrm{CH}_{3}\right)_{2} \mathrm{~S}$ levels and organoleptic test result $(p<0.001)$. Particularly, the correlation between the organoleptic test result and $\mathrm{CH}_{3} \mathrm{SH}$ level was markedly stronger than those between the organoleptic test result and $\mathrm{H}_{2} \mathrm{~S}$ and $\left(\mathrm{CH}_{3}\right)_{2} \mathrm{~S}$ levels $(r=0.906, p<0.001)$. $\left(\mathrm{CH}_{3}\right)_{2} \mathrm{~S}$ stimulates olfaction at $1 / 6$ and $1 / 21,000$ of the levels of $\mathrm{H}_{2} \mathrm{~S}$ and ammonia, respectively [13]. Accordingly, the strength of oral malodor is strongly correlated with the $\left(\mathrm{CH}_{3}\right)_{2} \mathrm{~S}$ level [14].

Of the subjects who visited the outpatient clinic for oral malodor during the 3 -year period, only 9 subjects $(2.5 \%)$ felt that they had no oral malodor and more than $80 \%$ of the examinees felt that they had oral malodor. However, only $54.3 \%$ of them were judged as having some level of oral malodor on the organoleptic test, showing no correlation between their self-perception and the organoleptic test results $(r=0.080, p=0.128)$. This finding suggests that persons who self-perceive oral malodor are not necessarily consistent with those who actually have it, and this finding was consistent with those of several reports $[14,15]$.

About $60 \%$ of the examinees felt oral dryness. A significant association was present between self-perception of oral malodor and oral dryness. Indeed, oral dryness due to reduced salivary flow is a cause of oral malodor [16], and the oral malodor level rises with a decrease in salivary flow [17]. On the other hand, feeling oral dryness was not significantly correlated in this study with the organoleptic test result, $\mathrm{H}_{2} \mathrm{~S}$, or $\mathrm{CH}_{3} \mathrm{SH}$, suggesting that a feeling of oral dryness does not necessarily indicate the actual reduction of salivary flow [18].

A significant association was also noted between selfperceptions of oral malodor and frequent tongue coating. Tongue coating has been reported to be one of the typical factors of oral malodor [19, 20]. Amou et al. [21] visually evaluated the accumulation of tongue coating using Kojima's 5-step scoring criteria [22] and observed its correlations with the organoleptic score and $\mathrm{CH}_{3} \mathrm{SH}$ level. Particularly, $\mathrm{F}$. nucleatum and T. denticola contained in tongue coating have been reported to be closely involved in VSC production [23, 24]. Therefore, tongue cleaning is recommended to improve oral malodor [25-28]. A significant correlation was noted between tongue coating and frequent tongue brushing $(r=$ $0.355, p<0.001$ ), possibly because patients know that tongue coating removal improves oral malodor. This was also demonstrated by the findings that frequent tongue brushing was inversely correlated with the organoleptic test result and $\mathrm{CH}_{3} \mathrm{SH}$ level.

A feeling of oral dryness was also significantly correlated with subjective symptoms causing oral complaints, such as intraoral viscosity and a strange taste. Similarly, a significant correlation was noted between a feeling of oral dryness and tongue coating $(p<0.001)$. These findings suggest that persons who feel oral dryness tend to have some oral complaints, and tongue coating induced their anxiety regarding oral malodor. Based on these findings, first null hypotheses that there is no correlation between self-perception of oral malodor and oral complaints was rejected.

It was also determined that there is no association between self-perception of oral malodor and its actual presence. Thus, the second null hypothesis was accepted. This is because examinees/patients suspected having oral malodor even though it was not present when there was some oral complaints such as, for example, the feeling of oral dryness, 
tongue coating, and a strange intraoral taste. Particularly, when oral dryness is felt, the person becomes sensitive to intraoral viscosity and an unpleasant taste, aggravating the tendency. Pseudohalitosis patients, that is, persons who visit outpatient clinics for oral malodor although it is actually absent, do not necessarily self-perceive oral malodor simply due to mental stress. The study results therefore suggest that some forms of oral complaints induced self-perception of oral malodor. On interviews of halitosis patients in actual medical practice, it is necessary to sufficiently ask whether they have discomfort in the oral cavity, in addition to asking about anxiety and mental distress due to oral malodor. If this is the case, not only mental support but also instruction and treatment should be offered to improve such oral complaints.

\section{Conclusions}

Our study revealed that the subjects with a self-perception of oral malodor were not necessarily consistent with those actually having an oral malodor. In addition, it was suggested that patients became aware of oral malodor when they felt oral complaints.

\section{Conflict of Interests}

The authors declare that there is no conflict of interests regarding the publication of this paper.

\section{Authors' Contribution}

Drs. Atsushi Kameyama and Sachiyo Tomita designed and coordinated the study. Dr. Yoichi Ishizuka managed the statistical analysis. Dr. Toshiko Sugiyama, DH. Kurumi Ishii, and DH. Chihiro Tatsuta performed data analysis. Dr. Toshiyuki Takahashi and Dr. Masatake Tsunoda assisted in the conceptualization and planning of the paper preparation. All authors reviewed the paper critically for content and approved it for submission.

\section{References}

[1] M. Sanz, S. Roldán, and D. Herrera, "Fundamentals of breath malodour," The Journal of Contemporary Dental Practice, vol. 2, no. 4, pp. 1-17, 2001.

[2] S. Tomita, A. Kameyama, N. Watanabe et al., "Analysis of clinical data from a specialized clinic for oral malodor at the Tokyo Dental College Chiba Hospital, 2009-2011," Nihon Shishubyo Gakkai Kaishi, vol. 55, no. 1, pp. 15-23, 2013.

[3] C. M. L. Bollen and T. Beikler, "Halitosis: the multidisciplinary approach," International Journal of Oral Science, vol. 4, no. 2, pp. 55-63, 2012.

[4] R. Seemann, M. Bizhang, C. Djamchidi, A. Kage, and S. Nachnani, "The proportion of pseudo-halitosis patients in a multidisciplinary breath malodour consultation," International Dental Journal, vol. 56, no. 2, pp. 77-81, 2006.

[5] F. Romano, E. Pigella, N. Guzzi, and M. Aimetti, "Patients' selfassessment of oral malodour and its relationship with organoleptic scores and oral conditions," International Journal of Dental Hygiene, vol. 8, no. 1, pp. 41-46, 2010.
[6] T. Murata, T. Yamaga, T. Iida, H. Miyazaki, and K. Yaegaki, "Classification and examination of halitosis," International Dental Journal, vol. 52, no. 3, pp. 181-186, 2002.

[7] T. Zaitsu, M. Ueno, K. Shinada, F. A. Wright, and Y. Kawaguchi, "Social anxiety disorder in genuine halitosis patients," Health and Quality of Life Outcomes, vol. 9, article 94, 2011.

[8] D. Van Steenberghe, P. Avontroodt, W. Peeters et al., "Effect of different mouthrinses on morning breath," Journal of Periodontology, vol. 72, no. 9, pp. 1183-1191, 2001.

[9] S. Awano, Y. Takata, I. Soh et al., "Correlations between health status and OralChroma ${ }^{\mathrm{TM}}$-determined volatile sulfide levels in mouth air of the elderly," Journal of Breath Research, vol. 5, no. 4, Article ID 046007, 2011.

[10] T. Sugiyama, A. Kameyama, and M. Tsunoda, "Effect of initial periodontal therapy in patients with halitosis," Journal of Japanese Academy of Malodor Syndrome, vol. 1, pp. 23-27, 2010.

[11] R. Nalçaci and I. S. Sönmez, "Evaluation of oral malodor in children," Oral Surgery, Oral Medicine, Oral Pathology, Oral Radiology, and Endodontology, vol. 106, no. 3, pp. 384-388, 2008.

[12] B. U. Aylikci and H. Çolak, "Halitosis: from diagnosis to management," Journal of Natural Science, Biology and Medicine, vol. 4, no. 1, pp. 14-23, 2013.

[13] Y. Nagata and N. Takeuchi, "Measurement of odor threshold value by triangle odor bag method," Bulletin of Japan Environmental Sanitation Center, vol. 17, pp. 77-89, 1990.

[14] M. Rosenberg, A. Kozlovsky, I. Gelernter et al., "Self-estimation of oral malodor," Journal of Dental Research, vol. 74, no. 9, pp. 1577-1582, 1995.

[15] M. Rosenberg, A. Kozlovsky, Y. Wind, and E. Mindel, "Selfassessment of oral malodor 1 year following initial consultation," Quintessence International, vol. 30, no. 5, pp. 324-327, 1999.

[16] I. Kleinberg, M. S. Wolff, and D. M. Codipilly, "Role of saliva in oral dryness, oral feel and oral malodour," International Dental Journal, vol. 52, no. 3, pp. 236-240, 2002.

[17] S. Koshimune, S. Awano, K. Gohara, E. Kurihara, T. Ansai, and T. Takehara, "Low salivary flow and volatile sulfur compounds in mouth air," Oral Surgery, Oral Medicine, Oral Pathology, Oral Radiology, and Endodontics, vol. 96, no. 1, pp. 38-41, 2003.

[18] M. Bergdahl and J. Bergdahl, "Low unstimulated salivary flow and subjective oral dryness: association with medication, anxiety, depression, and stress," Journal of Dental Research, vol. 79, no. 9, pp. 1652-1658, 2000.

[19] H.-X. Lu, C. Tang, X. Chen, M. C. M. Wong, and W. Ye, "Characteristics of patients complaining of halitosis and factors associated with halitosis," Oral Diseases, vol. 20, no. 8, pp. 787795, 2014.

[20] T. Kanehira, H. Hongo, J. Takehara et al., "A novel visual test for hydrogen sulfide on the tongue dorsum," Open Journal of Stomatology, vol. 02, no. 04, pp. 314-321, 2012.

[21] T. Amou, D. Hinode, M. Yoshioka, and D. Grenier, "Relationship between halitosis and periodontal disease-associated oral bacteria in tongue coatings," International Journal of Dental Hygiene, vol. 12, no. 2, pp. 145-151, 2014.

[22] K. Kojima, "Clinical studies on the coated tongue," Japanese Journal of Oral \& Maxillofacial Surgery, vol. 31, no. 7, pp. 1659$1678,1985$.

[23] T. Yasukawa, M. Ohmori, and S. Sato, “The relationship between physiologic halitosis and periodontopathic bacteria of the tongue and gingival sulcus," Odontology, vol. 98, no. 1, pp. 44-51, 2010. 
[24] R. Dinesh Kamaraj, S. B. Kara, and K. L. Vandana, "An evaluation of microbial profile in halitosis with tongue coating using PCR (polymerase chain reaction) - a clinical and microbiological study," Journal of Clinical and Diagnostic Research, vol. 8, no. 1, pp. 263-267, 2014.

[25] M. I. Van der Sleen, D. E. Slot, E. Van Trijffel, E. G. Winkel, and G. A. Van der Weijden, "Effectiveness of mechanical tongue cleaning on breath odour and tongue coating: a systematic review," International Journal of Dental Hygiene, vol. 8, no. 4, pp. 258-268, 2010.

[26] M. Quirynen, H. Zhao, and D. van Steenberghe, "Review of the treatment strategies for oral malodour," Clinical Oral Investigations, vol. 6, no. 1, pp. 1-10, 2002.

[27] D. Wilhelm, A. Himmelmann, C. Krause, and K. P. Wilhelm, "Short term clinical efficacy of new meridol halitosis tooth \& tongue gel in combination with a tongue cleaner to reduce oral malodor," The Journal of Clinical Dentistry, vol. 24, no. 1, pp. 1219, 2013.

[28] E. E. Aung, M. Ueno, T. Zaitsu, S. Furukawa, and Y. Kawaguchi, "Effectiveness of three oral hygiene regimens on oral malodor reduction: a randomized clinical trial," Trials, vol. 16, no. 1 , article 31, 2015. 


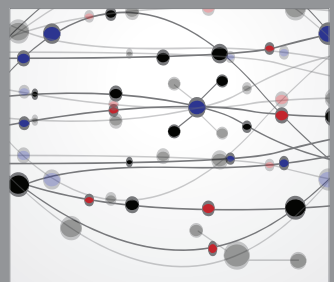

The Scientific World Journal
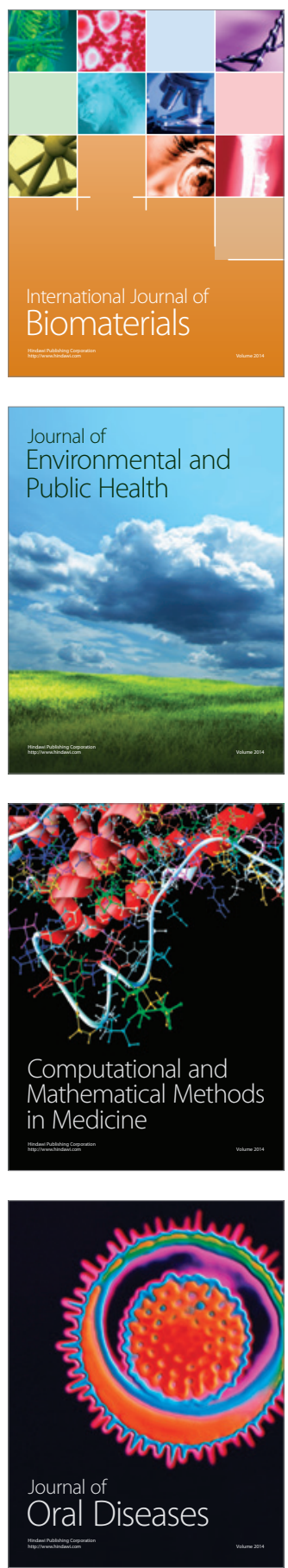
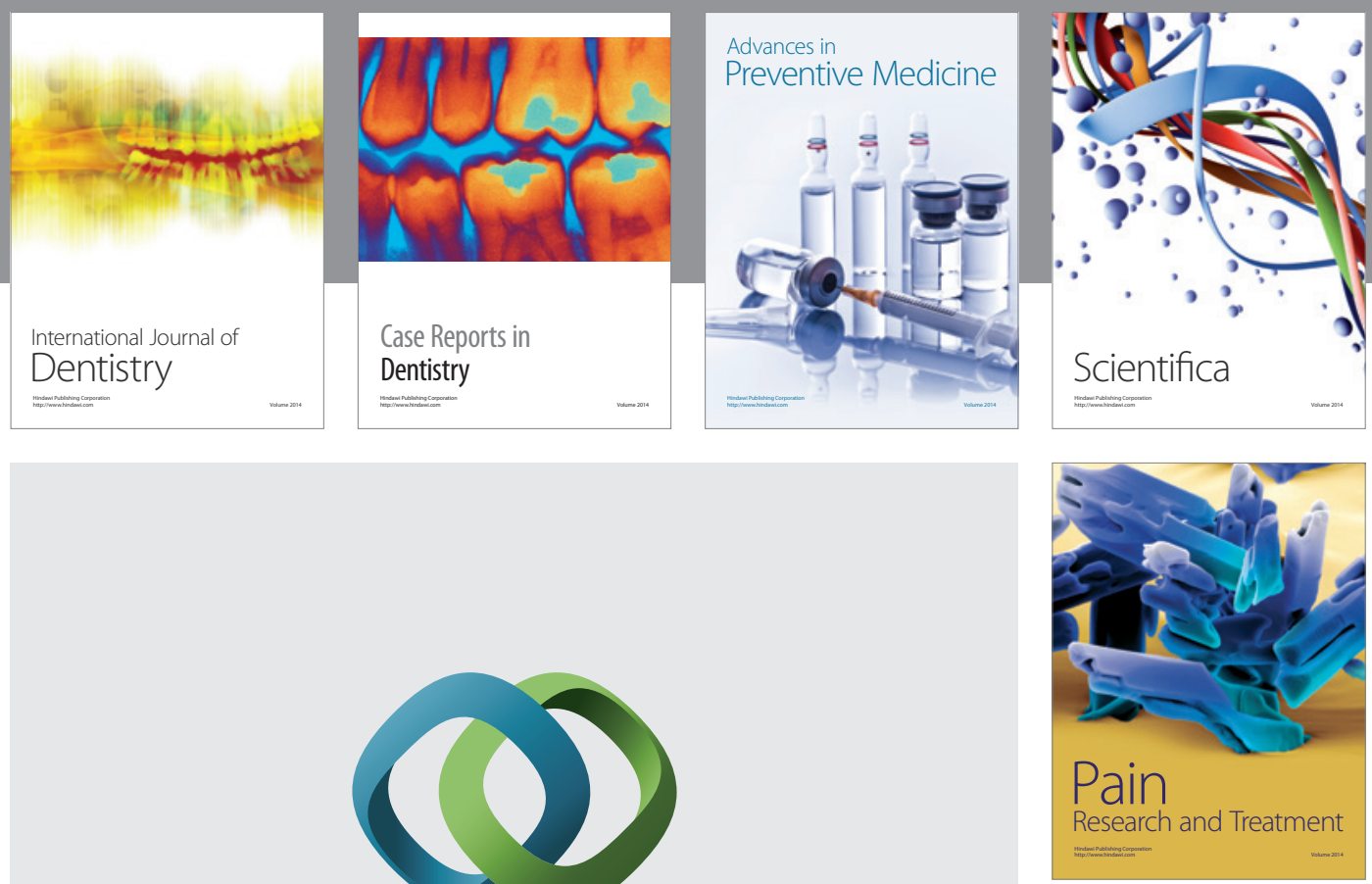

\section{Hindawi}

Submit your manuscripts at

http://www.hindawi.com
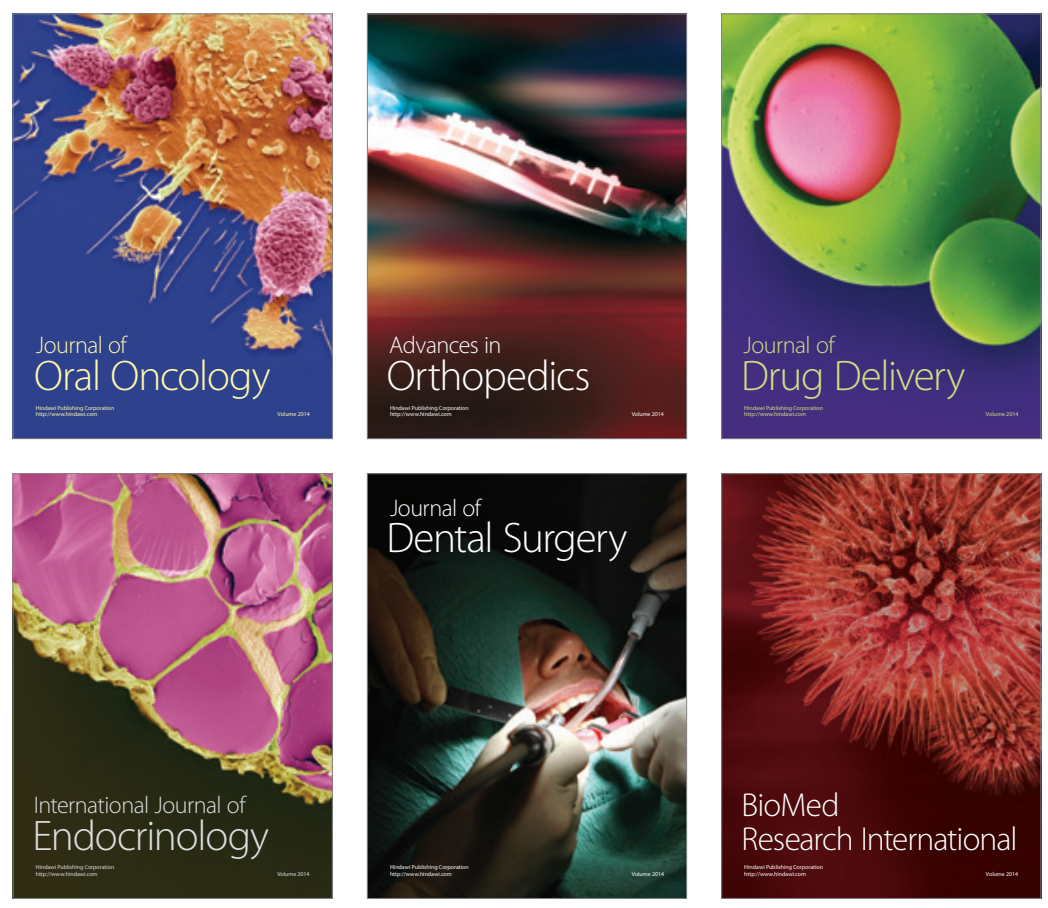

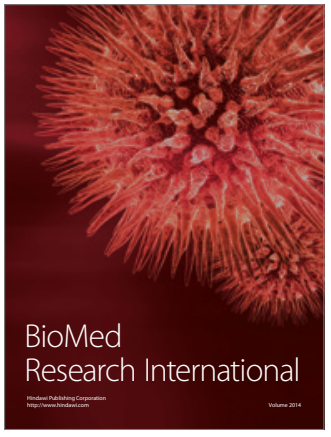

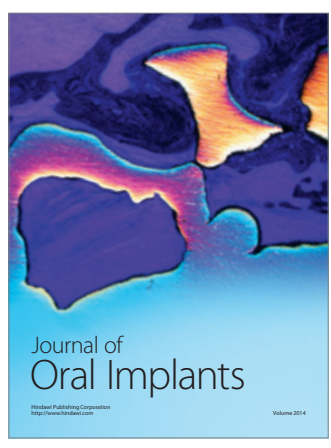
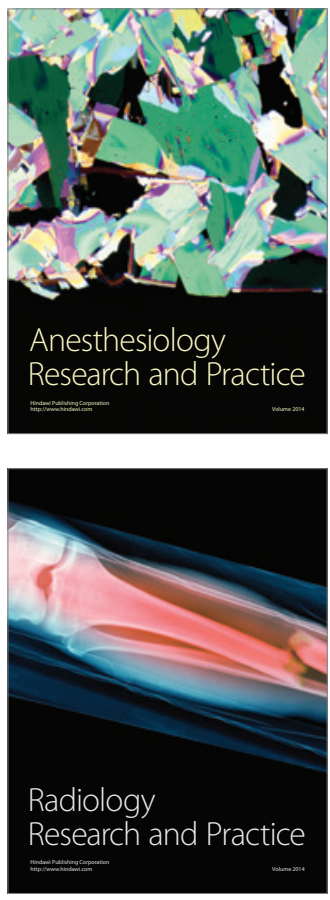